\title{
Intermittent Fasting Ameliorates Delayed-Type Hypersensitivity in NC/Nga Mice
}

\author{
Hirao Kohno ${ }^{1}$, Katsuyasu Kouda ${ }^{2}$, Hiroyasu Ishihara ${ }^{1}$, Nobuhiro Nishio ${ }^{3}$, Yutaka Sasaki ${ }^{1}$, Harunobu \\ Nakamura $^{4}$, Masayuki Iki ${ }^{2}$, Yoshiaki Sonoda ${ }^{1}$ \\ ${ }^{1}$ Department of Hygiene, Kansai Medical University, Moriguchi, Japan; ${ }^{2}$ Department of Public Health, School of Medicine, Kinki Univer- \\ sity, Sayama, Japan; ${ }^{3}$ Department of Public Health, Wakayama Medical University, Wakayama, Japan; ${ }^{4}$ Department of Health Promotion \\ and Education, Graduate School of Human Development and Environment, Kobe University, Kobe, Japan. \\ Email: konoh@takii.kmu.ac.jp
}

Received January $15^{\text {th }}$, 2011; revised February $13^{\text {th }}$, 2011; accepted March $17^{\text {th }}, 2011$.

\begin{abstract}
It is well documented that dietary restriction can prevent many different diseases and extend the life spans of different rodent species. In the previous study, we reported that intermittent fasting (IF) as well as moderate dietary restriction ameliorated the allergic dermatitis in ICR mice. In the present study, we demonstrated the ameliorative effects of IF on allergic dermatitis in NC/Nga mice, a strain known as a model for atopic dermatitis. Interestingly, the total number of $C D 4^{+} C D 8^{+}$double positive thymocyte in mice after IF significantly decreased in comparison to that in mice fed ad libitum. Although it was reported that an immunosuppressive compound inhibited the contact allergic response by inducing the $C D 4^{+} C D 25^{+}$regulatory T-cells, IF did not affect regulatory $T$ cells in the present study. These results suggested that $C D 4^{+} C D 8^{+}$double positive thymocytes play an important role in the regulation of allergy by IF in NC/Nga mice.
\end{abstract}

Keywords: Intermittent Fasting, Delayed-Type Hypersensitivity, Contact Dermatitis, Thymocyte

\section{Introduction}

Dietary restriction (DR) extends maximum and average lifespans in experimental animals [1,2]. Experimental studies have shown that such restriction can prevent or alleviate severity of spontaneously occurred-, chemically induced-, and radiation induced-neoplasia [3-5] and autoimmune diseases [6]. Two different DR protocols have proven effective in increasing life span and disease resistance in rats and mice. In one protocol animals are provided a daily food allotment that is typically $30 \%-40 \%$ less than the ad libitum (AL) consumption of a control population; this limited daily feeding protocol involves a controlled caloric restriction and a corresponding reduction in body weight. Intermittent fasting (IF), an another regimen of DR, alternates fasting ( 1 - 4 days) and refeeding repeatedly. It also has been reported to prolong the lifespan of rodents [7-10]. Recent study has suggested that IF can enhance health and cellular resistance to disease [7].

DR has been reported to exhibit preventive effects on allergic inflammation. Nohr et al. [11] reported the suppressive effect of short-term fasting on delayed-type hypersensitivity (DTH). It was reported that fasting during the sensitization phase suppressed DTH [12]. In addition, DR has also been reported to alleviate chemically induced ulcerative dermatitis [13]. Previously, we have reported that a moderate DR delayed onset and progression of spontaneous dermatitis in 14 week old NC/Nga mice through inhibiting infiltration of inflammatory cells and cytokines secretion [14]. Furthermore, we have demonstrated that short-term fasting in the challenge phase alleviated an allergic contact dermatitis caused by DTH in ICR mice [15]. It has been suggested that hypercorticism induced by nutritional stress is one of the major factors in the ameliorative effect of fasting on allergic dermatitis [16]. However, the details of immunological mechanisms involved in the alleviation of allergic dermatitis by fasting have not been elucidated. Therefore, in this study, we assessed the effect of IF on DTH induced by 2, 4- dinitrofulorobenzene (DNFB) in NC/Nga mice.

It has been reported that acute starvation results in the decline of T-cell cellularity in lymphoid tissues, especially thymus [17]. The greatest loss in thymocyte number with acute starvation was in the double-positive $\left(\mathrm{CD} 4^{+} \mathrm{CD} 8^{+}\right)$thymocyte subpopulation [18]. However, the effect of IF on the T-cell cellularity is unclear, we analyzed thymocytes and splenocytes of AL and IF mice 
by flow cytometry (FCM) on the basis of CD4 and CD8 expression.

Recent findings indicated that regulatory $\mathrm{T}$ (Treg) cells appears to be involved in regulating allergies [19]. Treg cells have been shown to inhibit the inappropriate immune responses involved in allergic diseases. Impaired expansion of Treg cells is hypothesized to lead to the development of allergy, and treatment to induce Treg cells could provide curative therapies for allergy. In fact, Weigmann et al. [20] have shown that the immunosuppressive compound leflunomide inhibited the contact allergic response induced by epicutaneous application of DNFB by inducing Treg cells. Thus, we investigated whether IF induce Treg cells in our study.

\section{Methods}

\subsection{Animal and Diet}

All experiments were approved by the Animal Experiment Committee of Kansai Medical University. Specific pathogen-free male NC/Nga mice obtained from Japan SLC (Hamamatsu, Japan) were used for the experiment. The mice were individually maintained in plastic cages in an environmentally controlled room with a $12 \mathrm{~h}$ lightdark cycle. Diet used in the experiments was a standard chow (MF; Oriental Yeast, Tokyo; Japan), containing $236 \mathrm{~g}$ protein, $53 \mathrm{~g}$ fat, $29 \mathrm{~g}$ fiber, and $61 \mathrm{~g}$ ash per $\mathrm{kg}$ of diet. The total digestible energy was $15.07 \mathrm{MJ}$ per $\mathrm{kg}$ of diet. The mice had free access to water throughout the study period. Body weights were recorded on day $0,1,3$, 4, 6 and 7.

\subsection{Induction of Dermatitis in the Mouse Ear}

Six weeks old mice (weight $21-26$ g) were randomly divided into four groups; AL DNFB (+), IF DNFB (+), AL DNFB (-) and IF DNFB (-). AL groups were allowed continuous access to laboratory diet. IF groups were fasted for $24 \mathrm{~h}$ intermittently with $48 \mathrm{~h}$ intervals. DNFB (+) groups were sensitized by a painting of $100 \mu \mathrm{l}$ of 0.5\% DNFB (Wako, Osaka, Japan) in acetone/olive oil (4:1) to the right ear. On Day 3 and Day 6, they were challenged by a painting of $20 \mu \mathrm{l}$ of $0.25 \%$ DNFB in acetone/olive oil (4:1) to the left ear. DNFB (-) groups were sensitized and challenged with acetone/olive oil $(4: 1)$.

Twenty four hours after the last challenge, the thickness of left ear was measured with a thickness gauge (Tecklock Corporation, Okaya, Japan) at a point $5.0 \mathrm{~mm}$ from the ear edge. Ears were taken from mice sacrificed by cervical dislocation at $24 \mathrm{~h}$ after the last challenge. Ears were fixed in $10 \%$ formalin, and embedded in paraffin. All ears were cut into $3 \mu \mathrm{m}$-thick sections at a point $5.0 \mathrm{~mm}$ from the ear edge. Sections were stained with hematoxylin and eosin, and observed microscopically.

\subsection{Analysis of Thymocyte and Splenocyte Cellularities}

Thymocytes and splenocytes in mice from AL DNFB (+) and IF DNFB $(+)$ groups were analyzed by flow cytometry. The cells were stained with phycoerythrin (PE) conjugated anti-CD4 antibodies (clone GK1.5, BD Biosciences, San Jose, CA) and fluorescein (FITC) conjugated anti-CD8 antibodies (clone 53-6.7, BD Biosciences). Cells $\left(2 \times 10^{6}\right)$ were incubated on ice with previously determined optimal concentrations of FITC or PE labeled antibodies for $30 \mathrm{~min}$. After staining, the cells were washed with PBS. Flow cytometric analyses were performed using a FACScan flow cytometer (BD Biosciences). Data were analyzed with CELLQUEST software (BD Biosciences).

\subsection{Analysis of Regulatory T Cell Population}

Intracellular staining for Foxp3 protein was carried out by using fixation and permeabilization buffers provided by the Mouse Regulatory T Cell Staining Kit (clone FJK16s, eBiosicence, San Diego, CA) according to the manufacturer's instructions. Population of Treg cell in splenocytes was quantified. CD4 and CD25 markers have been accepted as the Treg cell phenotypes. The splenocytes were adjusted to $1 \times 10^{7}$ cells/mL in flow staining buffer and stained with FITC-conjugated anti-CD4 monoclonal antibody (mAb) (clone RM4-5, eBiosicence) and APC-conjugated anti-CD25 mAb (clone PC61.5, eBiosicence). $\mathrm{CD}^{+} \mathrm{CD} 25^{+} \mathrm{T}$ cells were determined by FACScan.

\subsection{Statistical Analysis}

Unpaired t-test was used to determine significant differences of 2 groups. Two-way ANOVA was also used to determine significant differences among 4 groups. Values of $p<0.05$ were considered significant. All statistical analysis was performed using SPSS Base 11.5J for Windows (SPSS Inc., Chicago, IL).

\section{Results}

\subsection{Effect of IF on Body Weight and Ear Swelling}

In IF mice, the body weight fell acutely during the fasting periods, but rose again once feeding resumed to the same level of AL mice (Figure 1). These variations of body weight in IF mice were consistent with those in our previous study [16].

Ear swelling was observed in mice challenged with DNFB, while mice treated with vehicle exhibited no ear 
swelling at day 7 (Figure 2). The ear thickness in IF group was significantly smaller than that in AL group (533 $\pm 54.7 \mu \mathrm{m}$ [IF] vs. $725 \pm 103 \mu \mathrm{m}$, [AL]).

In AL DNFB (+) group, severe lymphocyte infiltration was not observed in dermis and severe edema was observed in subcutaneous tissue (Figures 3(a), (b)). On the other hand, there was no significant change in epidermis. Consequently, ear was thick. In IF DNFB $(+)$ group, these findings were moderate (Figures 3(c), (d)). In AL DNFB (-) and IF DNFB (-) groups, ear swelling was not observed (Figures 3(e), (f)).

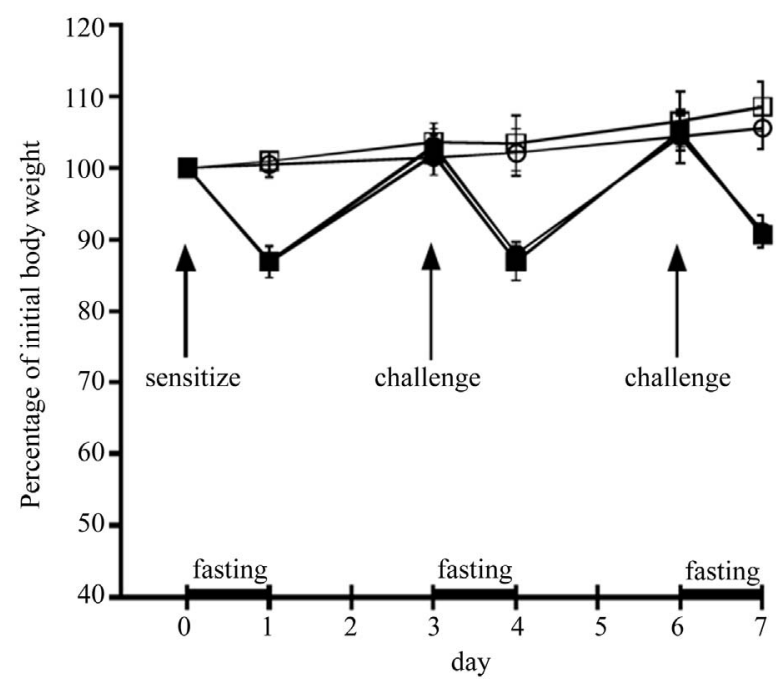

Figure 1. The effect of IF on body weight of NC/Nga mice. Body weight of $\mathrm{AL}$ DNFB(+) group ( $($ ), IF DNFB(+) group $(\bullet)$, AL DNFB(-) group ( $\square$ ), and IF DNFB(-) group (ø) mice were measured. All data are presented as the mean \pm S.D (n $=6$ ).

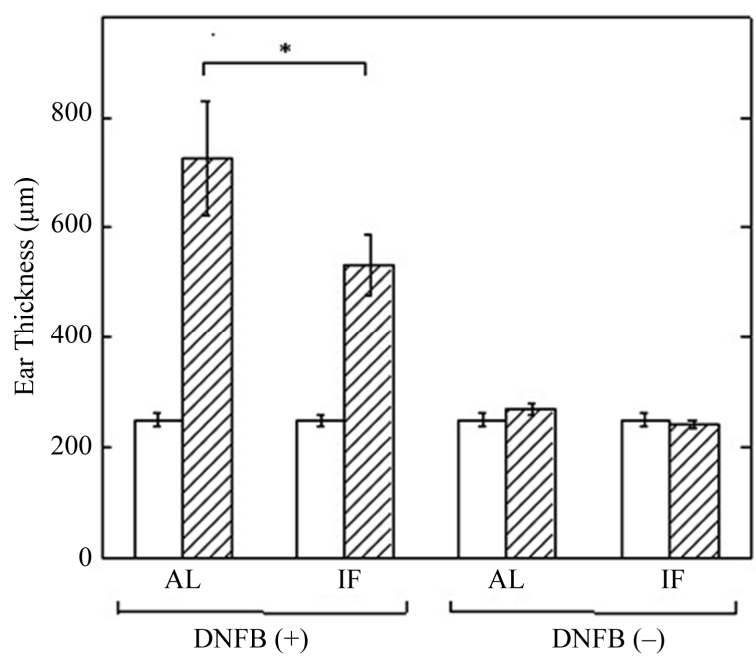

Figure 2. The effect of IF on DNFB-induced ear swelling in NC/Nga mice. Ear thickness was measured on day 0 (open column) and day 7 (shaded column). All data are presented as the mean \pm S.D $(n=6) .{ }^{*} P<0.01$.
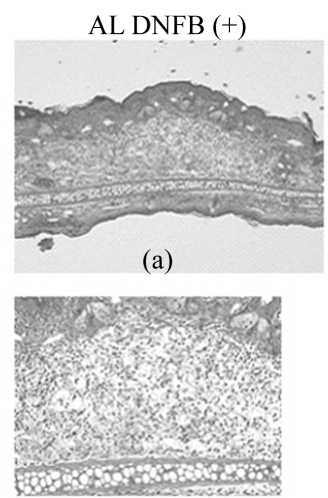

(c)

AL DNFB (-)

(e)

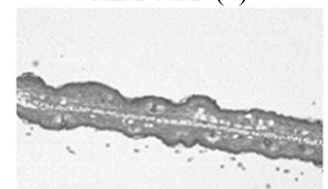

IF DNFB (+)

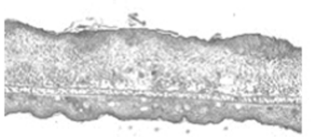

(b)

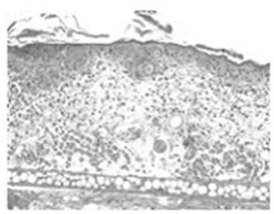

(d)

IF DNFB (-)

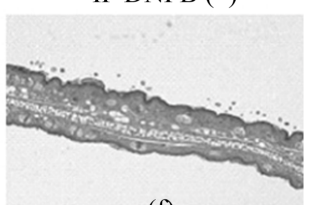

(f)
Figure 3. Effects of IF on histological features of the ear in NC/Nga mice on day 7. Hematoxylin and eosin sections are from the AL DNFB(+) group (a, b), IF DNFB(+) group (c, d), AL DNFB(-) group (e), and IF DNFB(-) group (f) mice. Sections are shown at $\times 40$ magnification $(a, c, e, f)$ or $\times 100$ magification $(b, d)$.

\subsection{Effect of IF on Cellularities of Thymocytes and Splenocytes}

Thymocytes and splenocytes from AL DNFB(+) and IF DNFB (+) mice were analyzed by FCM on the basis of CD4 and CD8 expression, and then total counts of thymocytes and splenocytes in each subset were calculated. (Figure 4). IF caused a dramatic fall in the mean total thymocyte count to $8.71 \%$ of that observed in AL mice (Figure 5(a)). This reduction in total thymic cellularity was mirrored by a reduction in the absolute numbers of $\mathrm{CD}^{+} \mathrm{CD}^{+}$and $\mathrm{CD} 4^{+} \mathrm{CD} 8^{-}$thymocyte subsets (Figure 5(a)).

The greatest effect of fasting was seen in the doublepositive $\mathrm{CD} 4^{+} \mathrm{CD} 8^{+}$thymocyte subpopulation. IF caused a reduction in both the absolute cell number (Figure 5(a)) and the overall relative proportion of $\mathrm{CD} 4^{+} \mathrm{CD} 8^{+}$thymocytes (56.5 $\pm 19.8 \%)$ compared with that observed in AL mice $(80.3 \pm 1.14 \%)$. Although IF caused a relative increase in the overall percentage of single-positive $\mathrm{CD} 4^{+}$ $\mathrm{CD}^{-}$thymocytes $(25.3 \pm 10.1 \%[\mathrm{IF}]$ vs. $14.1 \pm 0.59 \%$ [AL]), there was still a significant reduction in absolute numbers of this thymocyte subpopulation in the IF DNFB (+) mice compared with the AL DNFB (+) mice (Figure 5(a)).

IF resulted in a $44 \%$ reduction in the total number of splenocytes (Figure 5(b)). The absolute number of sple- 

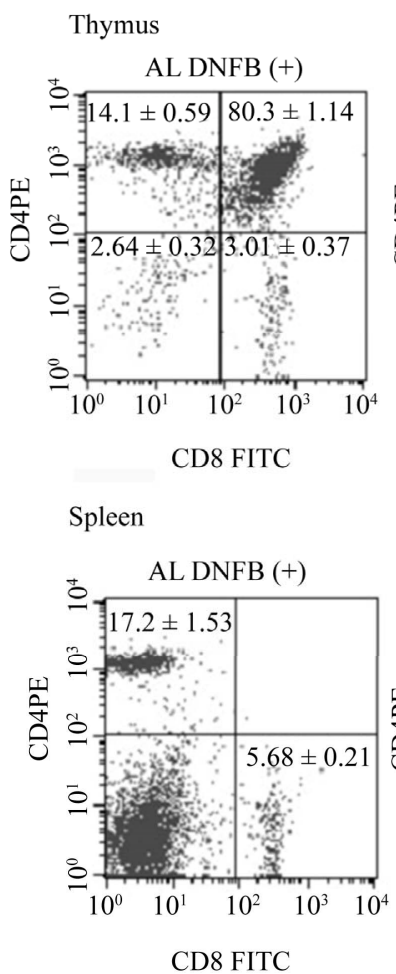
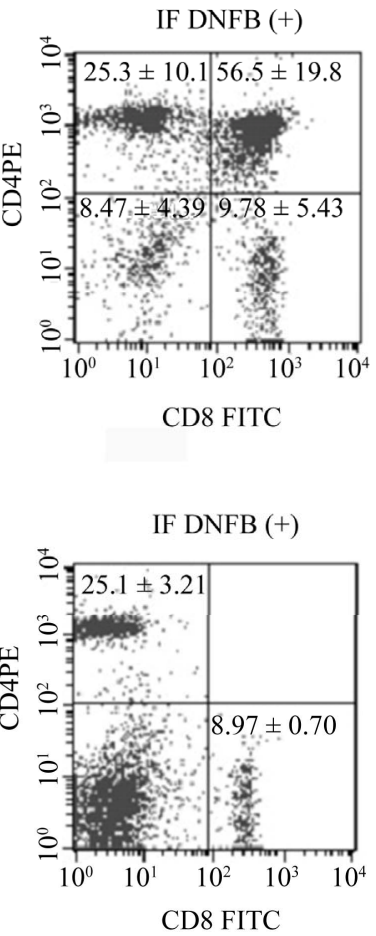

Figure 4. Representative flow-cytometric analysis of thymocytes and splenocytes stained for CD4 and CD8. Thymocytes and splenocytes from AL DNFB(+) and IF DNFB $(+)$ mice were analyzed by FCM on the basis of CD4 and CD8 expression. The number in each section represents the proportion of each subfraction and was presented as the mean \pm S.D $(n=6)$.

nocytes negative for both CD4 and CD8 (non-T cells) was particularly reduced by IF (39.1 \pm 15.6 million [IF] vs. $80.8 \pm 16.4$ million [AL]), while those of $\mathrm{CD}^{+} \mathrm{CD}^{-}$ or $\mathrm{CD} 4^{-} \mathrm{CD} 8^{+}$splenocytes were not significantly affected by IF.

\subsection{Effect of IF on Regulatory T Cell Population Units}

We attempted to elucidate whether IF induces the $\mathrm{CD} 4^{+}$ $\mathrm{CD} 25^{+}$Treg cells in NC/Nga mice. As shown in Figure 6, no significant difference in Treg cells proportion between $\mathrm{AL} \mathrm{DNFB}(+)$ group $(1.32 \pm 0.12 \%)$ and the IF DNFB $(+)$ group $(1.39 \pm 0.24 \%)$ was observed.

Therefore, it was concluded that amelioration of DTH by IF was not due to the induction of $\mathrm{CD} 4^{+} \mathrm{CD} 25^{+}$Treg cells in NC/Nga mice.

\section{Discussion}

Present study clearly demonstrated that IF exhibited the ameliorative effects on DTH induced by DNFB in NC/ Nga mice, a strain known as a model for human atopic dermatitis. The suppressive effect of fasting on DTH was

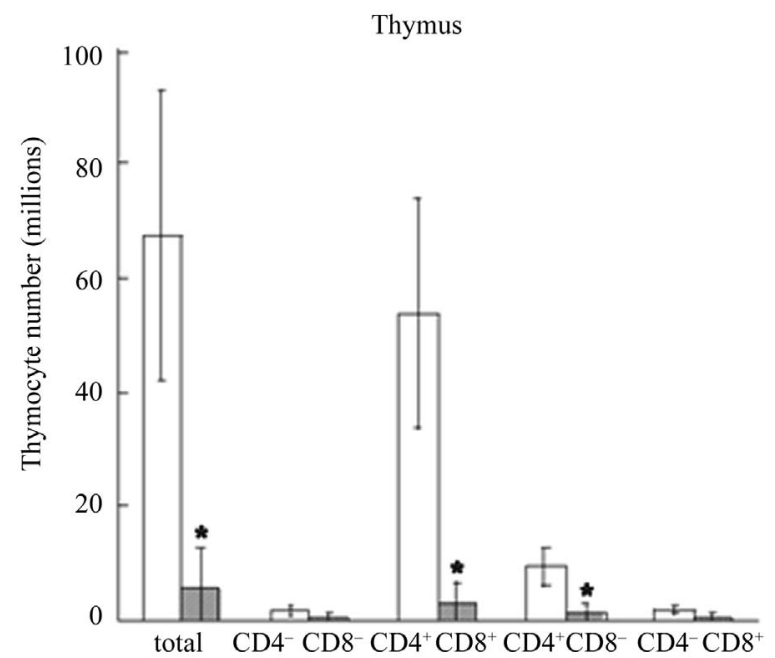

(a)

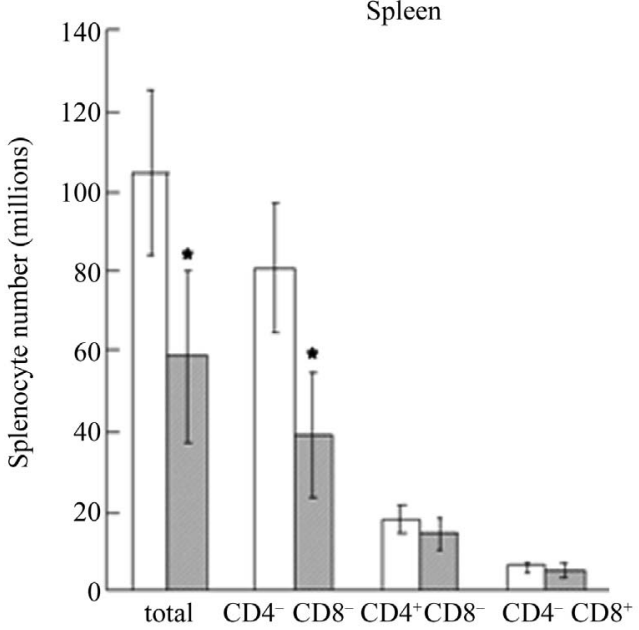

(b)

Figure 5. Effects of IF on thymocyte and splenocyte subpopulations in NC/Nga mice. Cell numbers of thymocytes (a) and splenocytes (b) in each subfractions were calculated based on FACS analysis data shown in Figure 4. Open column represent $\mathrm{AL}$ DNFB( + ) mice and shaded column represent IF $\mathrm{DNFB}(+)$ mice. All data are presented as the mean \pm S.D $(n=6) .{ }^{*} p<0.05$ vs. AL mice.

first reported by Lord et al. [12]. They showed that $48 \mathrm{~h}$ starvation during sensitization phase suppressed DTH induced by DNFB in C57BL/6J mice. Previously, we have reported that $24 \mathrm{~h}$ fasting after the challenge, as well as moderate $40 \%$ DR, could also ameliorate DTH induced by DNFB in ICR mice $[15,16]$. In the present study, using the same protocols for fasting and induction of DTH as in our previous study, we confirmed the ameliorative effect of IF on DTH in NC/Nga mice. Although the extent of ear swelling at $24 \mathrm{~h}$ after the last challenge was similar with ICR mice [15], the ameliorative effect of IF was more prominent in NC/Nga mice than in ICR mice. 

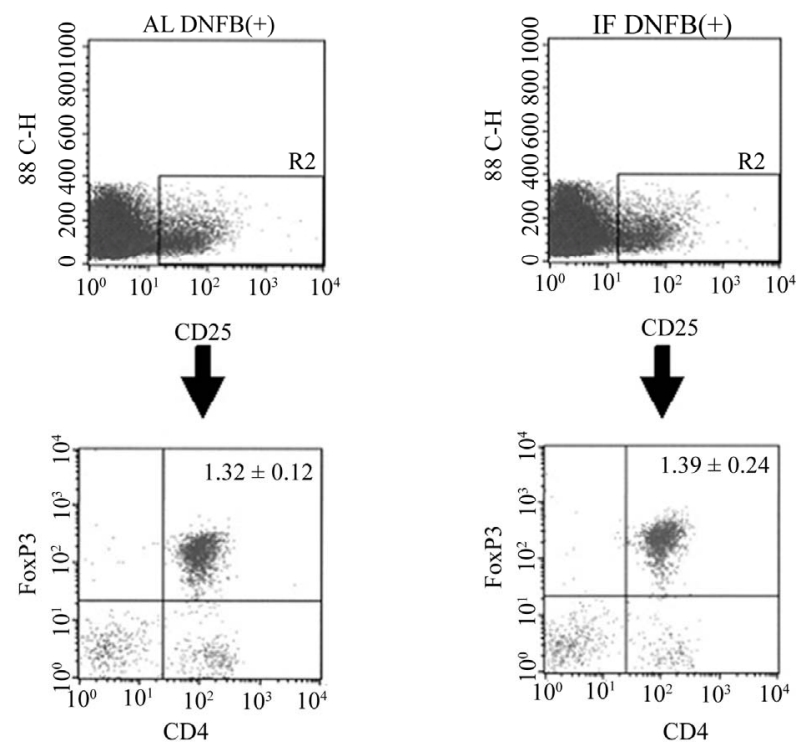

Figure 6. Representative flow-cytometric analysis of regulatory $T$ cells. Splenocytes from AL DNFB(+) and IF DNFB $(+)$ mice were stained for CD4 and CD25, followed by antiFoxp3 intracellular staining and analysis by flow cytometry. These results are representative of three different experiments. The number in each section represents the proportion of regulatory $T$ cells in total thymocytes and was presented as the mean \pm S.D $(n=6)$.

In mice starved for $48 \mathrm{~h}, 30 \%$ reduction in body weight was observed [12]. In mice fed with $40 \%$ restricted diet for 7 days, body weight fell by 13\% [16]. In contrast, both ICR [16] and NC/Nga (Figure 1) mice sustained the same body weight as that of AL mice after IF, since mice compensated for the loss in body weight during fasting periods by increasing their food intake and gaining weight during refeeding periods. In addition, any indication of malnutrition was not detected after IF [16]. Therefore, suppression of DTH could be achieved by DR protocol without malnutrition, such as IF. These results indicated that DR has ameliorative effect on DTH irrespective of DR protocol and mouse strains used.

Several mechanisms could contribute to the alleviation of allergic inflammation in dietary restricted mice. It has been well documented that acute starvation had a striking lympholytic effect in mice. Starvation results in the decline of T-cell cellularity in lymphoid tissues, especially thymus. In mice starved for $72 \mathrm{~h}$ the number of thymocytes fell by 95\% [17]. Howard et al. [18] reported that acute starvation for $48 \mathrm{~h}$ caused a dramatic fall in the mean total thymocyte count to $13 \%$ of that observed in control mice. They also demonstrated that the greatest loss in thymocyte number with acute starvation was in the double-positive $\left(\mathrm{CD}^{+} \mathrm{CD}^{+}\right)$thymocyte subpopulation. In the present study, cellularity of thymocytes in NC/Nga mice after IF decreased to $8.71 \%$ of that in AL mice and the greatest loss in thymocyte number was in the double-positive $\left(\mathrm{CD}^{+} \mathrm{CD}^{+}\right)$thymocyte subpopulation (Figure 5).

According to the study by Wing et al. [17], the cellularity of thymocytes continued to fall during the first 2 days of refeeding and then began to return towards normal. Therefore, it takes longer time to recover than fasting period once the lymphoid atrophy in thymus occur. In our IF protocol, next fasting period starts before mice recover from the lymphoid atrophy in thymus during refeeding period, which would cause accumulative effects on the cellularity of thymus. Thus, IF resulted in the reduction of thymocyte cellularity (Figure 5), which is comparable with that of starvation for 48 to $72 \mathrm{~h}$.

Two factors have been regarded as probable cause of starvation-induced lymphoid atrophy. First, it is well known that corticosterone induces lymphoid atrophy and malnutrition is associated with increased secretion of corticosterone [21,22]. In addition, Klebanov et al. [23] reported that hyperadrenocorticism attenuated inflammation during food restriction in mice. Studies by Wing et al. [17] on the mechanism of lympholysis suggest that the adrenal glands help to regulate lymphocyte cellularity since the lympholytic effect of starvation was mostly eliminated in adrenalectomized mice. From these findings, it could be concluded that increased corticosteroid secretion during the stress of starvation resulted in marked lympholysis. With regard to the effect of corticosteroid, we have previously shown that administration of glucocorticoid receptor antagonist, RU486, reversed the suppressive effect of IF on DTH [16]. Therefore, in NC/Nga mice, it seems likely that corticosteroid secretion was induced by IF, which may cause lymphoid atrophy in thymus and amelioration of DTH.

Another factor which controls starvation-induced lymphoid atrophy is leptin. Previously, Lord et al. [12] demonstrated that administration of leptin, which is acknowledged to decrease by fasting or DR [12,24-26], to fasted mice reversed the immunosuppressive effects of fasting on DTH. Furthermore, Howard et al. [18] have shown that exogenous leptin, administered only during the period of fasting, was able to protect completely against the thymic atrophy induced by acute starvation. Since it has been shown that the plasma leptin level of male C57BL/6J mice that had fasted for $24 \mathrm{~h}$ was reduced to $14.2 \%$ of the control [27], it seems likely that decreased level of leptin caused by IF is one of possible mechanisms involved in the amelioration of DNFB-induced DTH in NC/Nga mice.

It has been accepted that Treg cells are involved in regulating allergies [19]. Treg cells have been shown to inhibit the inappropriate immune responses involved in allergic diseases and induction of Treg cells could pro- 
vide curative therapies for allergy [20]. Although we investigated whether IF induce Treg cells in our study, IF could not induce Treg cells in NC/Nga mice (Figure 6). Recently, it has been demonstrated that leptin acts as a negative signal for the proliferation of Treg cells [28]. Since serum leptin levels decline in fasted mice [27], it is suggested that IF protocol in our study could not cause a decrease in serum leptin to a level which is low enough to induce the proliferation of Treg cells.

In summary, we herein demonstrated that 1) IF ameliorated DNFB-induced DTH in NC/Nga mice and 2) a marked decrease in cellularity of thymocytes, mainly in the double-positive $\left(\mathrm{CD} 4^{+} \mathrm{CD}^{+}\right)$subpopulation was observed in IF mice. These results provide a new evidence that IF exhibits an ameliorative effect on allergic dermatitis through the reduction in thymocyte cellularity.

\section{Acknowledgements}

This work was supported by grant from Kansai Medical University (Research grant C).

\section{REFERENCES}

[1] B. P. Yu, "Aging and Oxidative Stress: Modulation by Dietary Restriction,” Free Radical Biology and Medicine, Vol. 21, No. 5, 1996, pp. 651-668. doi:10.1016/0891-5849(96)00162-1

[2] R. Weindruch and R. S. Sohal, "Caloric Intake and Aging,” New England Journal of Medicine, Vol. 337, No. 14, 1997, pp. 986-994. doi:10.1056/NEJM199710023371407

[3] R. Weindruch and R. L. Walford, "The Retardation of Aging and Disease by Dietary Restriction,” Charles C Thomas Pub. Ltd., Springfield, 1988.

[4] D. F. Birt, A. Yaktine and E. Duysen, "Glucocorticoid Mediation of Dietary Energy Restriction Inhibition of Mouse Skin Carcinogenesis," The Journal of Nutrition, Vol. 129, No. 2S, 1999, pp. 571S-574S.

[5] K. Yoshida, T. Inoue, K. Nojima, Y. Hirabayashi and T. Sado, "Calorie Restriction Reduces the Incidence of Myeloid Leukemia Induced by a Single Whole-Body Radiation in C3H/He Mice," Proceedings of National Academy of Sciences U. S. A., Vol. 94, No. 6, 1997, pp. 2615-2619. doi:10.1073/pnas.94.6.2615

[6] C. Kubo, A. Gajjar, B. C. Johnson and R. A. Good, "The Effects of Dietary Restriction on Immune Function and Development of Autoimmune Disease in BXSB Mice," Proceedings of National Academy of Sciences U. S. A., Vol. 89, No. 7, 1992, pp. 3145-3149.

[7] R. M. Anson, Z. Guo, R. de Cabo, T. Iyun, M. Rios, A. Hagepanos, D. K. Ingram, M. A. Lane and M. P. Mattson, "Intermittent Fasting Dissociates Beneficial Effects of Dietary Restriction on Glucose Metabolism and Neuronal Resistance to Injury from Calorie Intake," Proceedings of National Academy of Sciences U. S. A., Vol. 100, No. 10, 2003, pp. 6216-6220. doi:10.1073/pnas.1035720100

[8] C. L. Goodrick, D. K. Ingram, M. A. Reynolds, J. R.
Freeman and N. Cider, "Effects of Intermittent Feeding upon Weight and Lifespan in Inbred Mice: Interaction of Genotype and Age," Mechanisms of Ageing and Development, Vol. 55, No. 1, 1990, pp. 69-87. doi:10.1016/0047-6374(90)90107-Q

[9] E. A. Hsieh, C. M. Chai and M. K. Hellerstein, "Effects of Caloric Restriction on Cell Proliferation in Several Tissues in Mice: Role of Intermittent Feeding,” American Journal of Physiology Endocrinology and Metabolism, Vol. 288, No. 5, 2005, pp. E965-E972. doi:10.1152/ajpendo.00368.2004

[10] H. Sogawa and C. Kubo, "Influence of Short-Term Repeated Fasting on the Longevity of Female $($ NZB $\times$ NZW) F1 Mice,” Mechanisms of Ageing and Development, Vol. 115, No. 1-2, 2000, pp. 61-71. doi:10.1016/S0047-6374(00)00109-3

[11] C. W. Nohr, J. I. Tchervenkov, J. L. Meakins and N. V. Christou, "Malnutrition and Humoral Immunity: Shortterm Acute Nutritional Deprivation,” Surgery, Vol. 98, No. 4, 1985, pp. 769-776.

[12] G. M. Lord, G. Matarese, J. K. Howard, R. J. Baker, S. R. Bloom, and R. I. Lechler, "Leptin Modulates the T-Cell Immune Response and Reverses Starvation-Induced Immunosuppression,” Nature, Vol. 394, No. 6696, 1998, pp. 897-901. doi:10.1038/29795

[13] S. N. Perkins, S. D. Hursting, J. M. Phang and D. C. Haines, "Calorie Restriction Reduces Ulcerative Dermatitis and Infection-Related Mortality in p53-Deficient and Wild-Type Mice,” Journal of Investigative Dermatology, Vol. 111, No. 2, 1998, pp. 292-296. doi:10.1046/j.1523-1747.1998.00270.x

[14] W. Fan, K. Kouda, H. Nakamura and H. Takeuchi, "Effects of Dietary Restriction on Spontaneous Dermatitis in NC/Nga Mice,” Experimental Biology and Medicine, Vol. 226, No. 11, 2001, pp. 1045-1050.

[15] H. Nakamura, K. Kouda, W. Fan, T. Watanabe and H. Takeuchi, "Suppressive Effects on Allergic Contact Dermatitis by Short-Term Fasting,” Toxicological Pathology, Vol. 29, No. 2, 2001, pp. 200-207. doi:10.1080/019262301317052477

[16] H. Nakamura, K. Kouda, R. Tokunaga and H. Takeuchi, "Suppressive Effects on Delayed Type Hypersensitivity by Fasting and Dietary Restriction in ICR Mice," Toxicological Letters, Vol. 146, No. 3, 2004, pp. 259-267. doi:10.1016/j.toxlet.2003.10.008

[17] E. J. Wing, D. M. Magee and L. K. Braczynski, “Acute Starvation in Mice Reduces the Number of $\mathrm{T}$ Cells and Suppresses the Development of T-Cell-Mediated Immunity,” Immunology, Vol. 63, No. 4, 1988, pp. 677-682.

[18] J. K. Howard, G. M. Lord, G. Matarese, S. Vendetti, M. A. Ghatei, R. I. Lechler and S. R. Bloom, "Leptin Protects Mice from Starvation-Induced Lymphoid Atrophy and Increases Thymic Cellularity in Ob/Ob Mice,” Journal of Clinical Investigation, Vol. 104, No. 8, 1999, pp. 1051-1059. doi:10.1172/JCI6762

[19] P. Stock, R. H. DeKruyff and D. T. Umetsu, "Inhibition of the Allergic Response by Regulatory T Cells. Mechanisms of Allergy and Adult Asthma," Current Oppinion 
in Allergy and Clinical Immunology, Vol. 6, No. 1, 2006, pp. 12-16. doi:10.1097/01.all.0000200502.69672.44

[20] B. Weigmann, E. R. Jarman, S. Sudowe, M. Bros, J. Knop and A. B. Reske-Kunz, "Induction of Regulatory T Cells by Leflunomide in a Murine Model of Contact Allergen Sensitivity,” Journal of Investigative Dermatology, Vol. 126, No. 7, 2006, pp. 1524-1533. doi:10.1038/sj.jid.5700228

[21] J. D. Stinnet, "Nutrition and the Immune Response," CRC Press Inc., Boca Raton, 1983.

[22] R. R. Watson, C. Chien and C. Chung, “Thymosin Treatment: Serum Corticosterone and Lymphocyte Mitogenesis in Moderately and Severely Protein-Malnourished Mice,” Journal of Nutrition, Vol. 113, No. 3, 1983, pp. 483-493.

[23] S. Klebanov, S. Diais, W. B. Stavinoha, Y. Suh and J. F. Nelson, "Hyper-Adrenocorticism, Attenuated Inflammation, and the Life-Prolonging Action of Food Restriction in Mice," Journal of Gerontology-Series A, Vol. 50, No. 2, 1995, pp. B78-B82.

[24] R. S. Ahima, D. Prabakaran, C. Mantzoros, D. Qu, B. Lowell, E. Maratos-Flier and J. S. Flier, "Role of Leptin in the Neuroendocrine Response to Fasting," Nature, Vol.
382, No. 6588, 1996, pp. 250-252. doi:10.1038/382250a0

[25] R. Faggioni, A. Moser, K. R. Feingold and C. Grunfeld, "Reduced Leptin Levels in Starvation Increase Susceptibility to Endotoxic Shock," American Journal of Pathology, Vol. 156, No. 5, 2000, pp. 1781-1787. doi:10.1016/S0002-9440(10)65049-3

[26] S. Gregersen, J. L. Thomsen, P. B. Jeppesen, K. K. Alstrup, B. Brock, S. B. Pedersen, K. Kristensen and K. Hermansen, "Impact of Dietary FA and Energy Restriction on Plasma Leptin and Ob Gene Expression in Mice,” Lipids, Vol. 38, No. 5, 2003, pp. 513-517. doi:10.1007/s11745-003-1092-y

[27] M. Higashimoto, M. Sano, M. Kondo and M. Sato, “Different Responses of Metallothionein and Leptin Induced in the Mouse by Fasting Stress," Biological Trace Element Research, Vol. 89, No. 1, 2002, pp. 75-84. doi:10.1385/BTER:89:1:75

[28] V. De Rosa, C. Procaccini, G. Pirozzi, S. Fontana, S. Zappacosta, A. L. Cava and G. Matarese, et al., "A Key Role of Leptin in the Control of Regulatory T Cell Proliferation,” Immunity, Vol. 26, No. 2, 2007, pp. 241-255. doi:10.1016/j.immuni.2007.01.011 